\title{
THE INFLUENCE OF WIDE DEFORMATION RANGE ON THE AUSTENITIC TRANSFORMATIONS OF THE P620Q STEEL
}

\author{
Rostislav KAWULOK, David ŠKANDERA, Petr KAWULOK, Ivo SCHINDLER, Tomáš KUBINA, \\ Vojtěch ŠEVČÁK
}

\author{
VSB - Technical University of Ostrava, Ostrava, Czech Republic, EU, \\ rostislav.kawulok@vsb.cz
}

https://doi.org/10.37904/metal.2019.691

\begin{abstract}
Based on dilatometry tests, the effect of various values of previous deformation on the kinetics of austenite transformations during the cooling of $\mathrm{P} 620 \mathrm{Q}$ steel has been studied. Dilatometry tests have been performed with the use of the optical dilatometry module of the plastometer Gleeble 3800. The obtained results were confronted with the metallographic analyses and hardness measurements HV30. Uniaxial compression deformations were being chosen as follows: $0,0.15,0.35,0.7,1$, and 2; note, these are true (logarithmic) deformations. The strain rate of $1 / \mathrm{s}$ was used in each case. It was verified, an increasing deformation value causes the growth of the ferrite and pearlite start-temperatures - especially in the areas of higher cooling rates. Based on this, the assumption of acceleration of by-diffusion-driven transformations through the previous deformation has been again verified. With the increasing of previous deformation, a bainite-start temperature was being proportionally growing in the entire range of cooling rates. Nevertheless, the effect of the increasing previous deformation was in the case of a martensite-start temperature entirely opposite.
\end{abstract}

Keywords: Transformation, austenite, dilatometry tests, microstructure, deformation

\section{INTRODUCTION}

Many factors influence the conversion of austenite during steel cooling and thus also the resulting structure and consequently mechanical properties. The chemical composition of the steel has a fundamental influence, but also the cooling rate, the initial structure, the deformation and strain rate [1-3]. Transformation diagrams of type (D)CCT (Deformation) Continuously Cooling Transformation, are used to describe the austenite transformation kinetics in each range of cooling rates for a particular chemical composition and deformation characteristic [3-5].

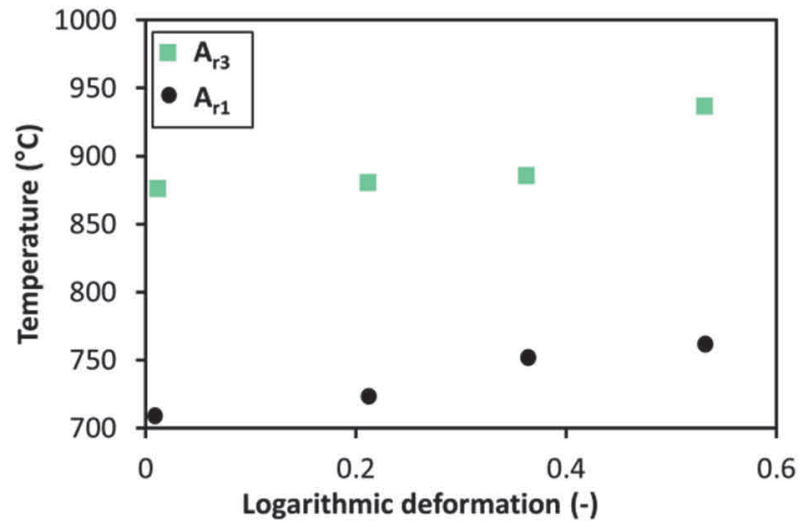

Figure 1 Effect of deformation on ferritic transformation of HSLA steel [12].

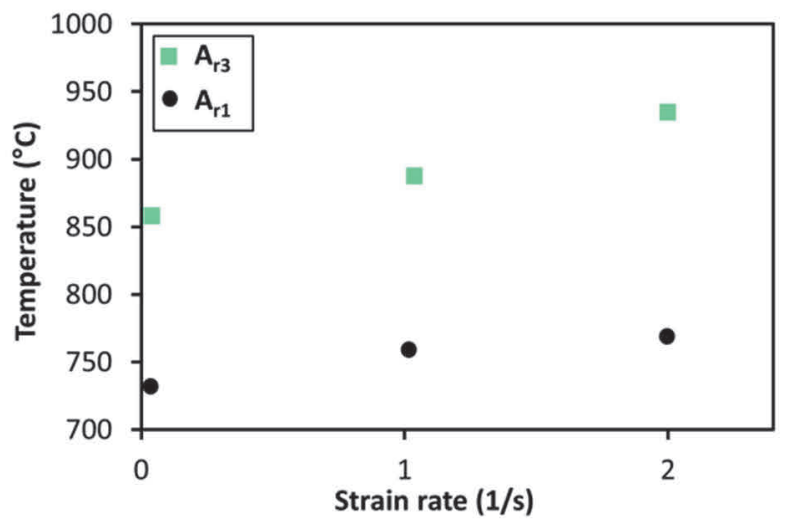

Figure 2 Effect of strain rate on ferritic transformation of HSLA steel [12]. 
There is a fair amount of data to suggest that the prior deformation affects the transformations of sub-eutectoid steels in the sense of acceleration, especially of ferritic and pearlitic transformation [6-10]. However, there are not many records of the effect of different deformation sizes [11,12]. One of the few experiments on structural carbon steel assumes that as the magnitude of deformation increases, the temperature of the origin of ferrite and pearlite formation increases - see Figure 1. Similarly, the effect of the strain rate - see Figure 2. In both cases, it is assumed that the increasing deformation also increases the diffusion of atoms and in the structure, it creates more germinal sites, which further grow and thus accelerate the transformation of austenite to ferrite, possibly pearlite, which are both products of diffusion transformations. However, the results are not so unambiguous when assessing the influence of different deformation sizes on bainite and martensite [11,12].

The aim of this paper was to assess the various sizes of the previous deformation on the transformation changes of austenite during cooling of $\mathrm{P} 620 \mathrm{Q}$ steel. This post eutectoid low-carbon alloy steel is of high quality and is mainly used to produce seamless pipes and cylinders. The chemical composition of the ivestigated steel is shown in Table 1 [13].

Table 1 Chemical composition of the P620Q steel in wt. \% [13].

\begin{tabular}{|c|c|c|c|c|c|c|c|}
\hline $\mathbf{C}$ & $\mathbf{S i}$ & $\mathbf{M n}$ & $\mathbf{N i}$ & $\mathbf{P}$ & $\mathbf{S}$ & $\mathbf{C r}$ & Mo \\
\hline $\max 0.2$ & $\max 0.6$ & $1-1.7$ & $\max 0.8$ & $\max 0.025$ & $\max 0.02$ & $\max 0.3$ & $\max 0.1$ \\
\hline
\end{tabular}

\section{EXPERIMENTAL DESCRIPTION}

The experiment was based on dilatometry tests supported by metallographic analyses and HV30 hardness measurements. Dilatometry tests were carried out on an optical dilatometry module, which in combination with the Gleeble plastometer allows measurement in a wide range of transverse dimensions and thus also of deformations. For the experiment, cylindrical samples with a diameter of $6 \mathrm{~mm}$ and a length of $86 \mathrm{~mm}$ were prepared from the studied steel. These samples were uniformly austenitized at $900{ }^{\circ} \mathrm{C}$ and $180{ }^{\circ} \mathrm{C}$ with stabilization at this temperature. This was followed by deformation by uniaxial pressure of the magnitude of the actual deformation of $0.15 ; 0.35 ; 0.7 ; 1$ and 2 . The strain rate was $1 / \mathrm{s}$ in all cases. Deformation was followed by continuous cooling at constant rates of $0.2 ; 1 ; 4 ; 10 ; 20$ and $35{ }^{\circ} \mathrm{C} / \mathrm{s}$. For supplementation, the samples were also cooled without prior deformation. A diagram of dilatometry experiments is provided in Figure 3.

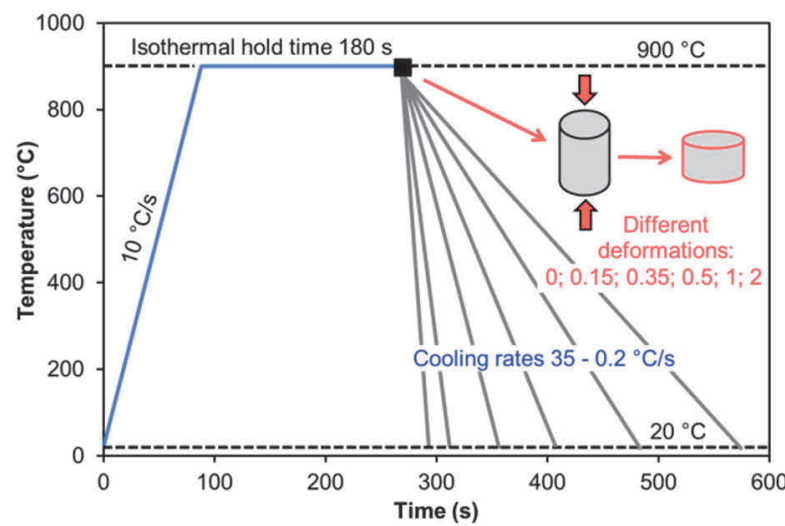

Figure 3 Diagram showing the dilatometry experiment using previous deformation.

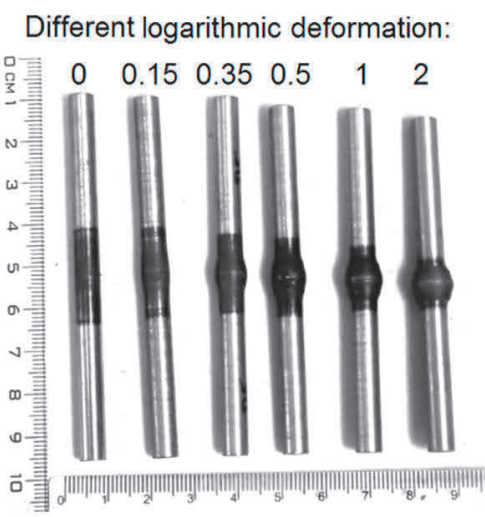

Figure 4 Tested samples after all modes of deformation

By analyzing the dilatometry curves obtained, (D)CCT diagrams for individual deformations were constructed. Semi-automatic CCT software, which is part of the dilatometry module and thus the plastometer Gleeble, was used to construct the transformation diagrams and analyze the data. Examples of samples after all deformation variants are given in Figure 4. 


\section{DISCUSSION OF RESULTS:}

From our own experience and based on the study of foreign sources [14, 15], a combination of the tangent method and derivative of the dilatation curve was chosen for the correct determination of coordinates of specific transformations in CCT software. An example of this evaluation is given in Figure 5, which demonstrates this method on a sample after a size 2 of deformation and the cooling rate of $0.2^{\circ} \mathrm{C} / \mathrm{s}$.

Figure 6 then shows a comparison of dilatometry curves, including localized transformation points for a cooling rate of $20^{\circ} \mathrm{C} / \mathrm{s}$.

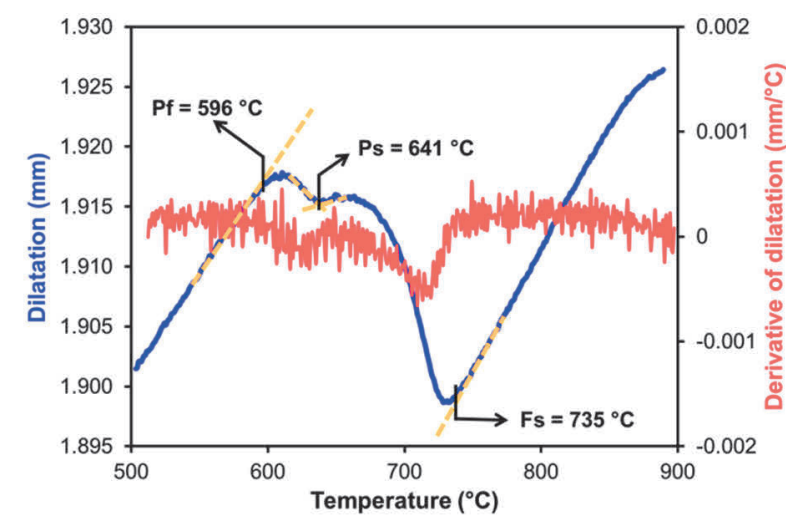

Figure 5 Example of evaluation of the combination of the tangent method and the derivative of the dilatation curve for a sample cooled at $0.2^{\circ} \mathrm{C} / \mathrm{s}$ and deformation 2

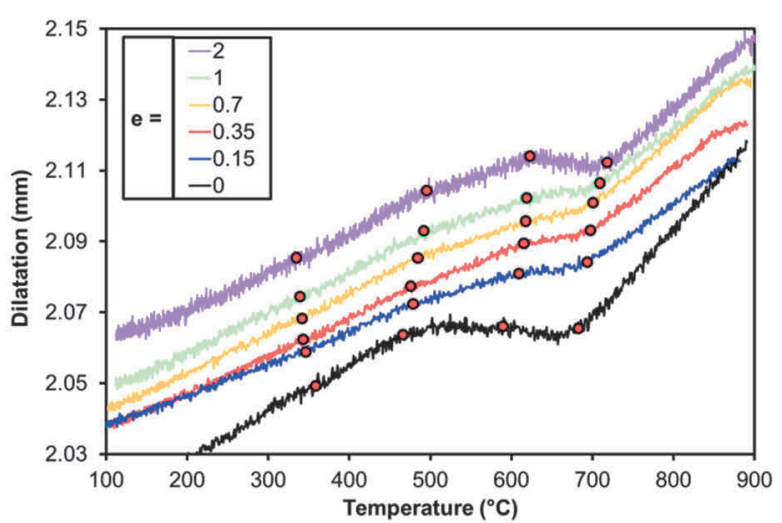

Figure 6 localized austenitic transformation points for a cooling rate of $20^{\circ} \mathrm{C} / \mathrm{s}$ and the entire range of deformation studied

The obtained coordinates of the individual transformations for the entire tested range of deformations and cooling rates were entered in the (D)CCT diagram (Figure 7), which demonstrates the influence of these parameters on a particular region of austenite transformation.

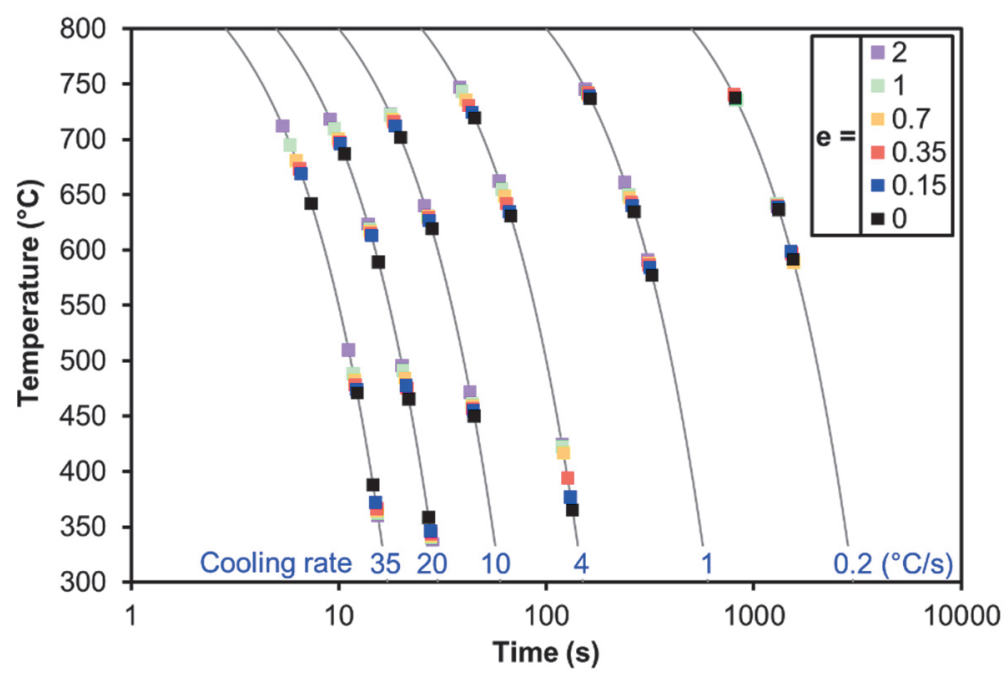

Figure 7 Comparative (D)CCT diagram including the entire tested range of deformations

The accuracy of dilatometry measurements was also supported by metallographic analyses using classical optical - light metallography, which was used in combination with the QuickPHOTO INDUSTRIAL evaluation software to distinguish individual structural components. Selected examples of microstructures are shown in Figures 8-10. 
The microstructure of samples after cooling at a rate of $0.2^{\circ} \mathrm{C} / \mathrm{s}$ is, in all cases of the selected deformation, comprised solely of ferrite and pearlite, whereas there is only a slight difference in the proportion of individual structural components and possibly the size of the ferritic grains (Figure 8).

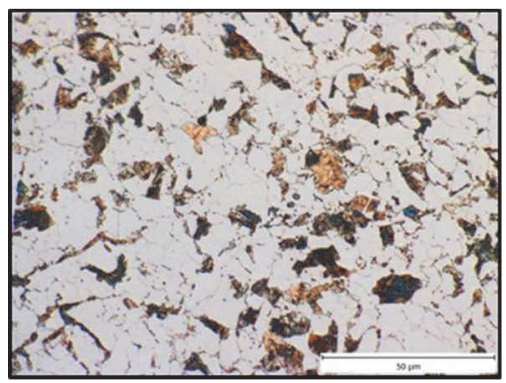

Without deformation

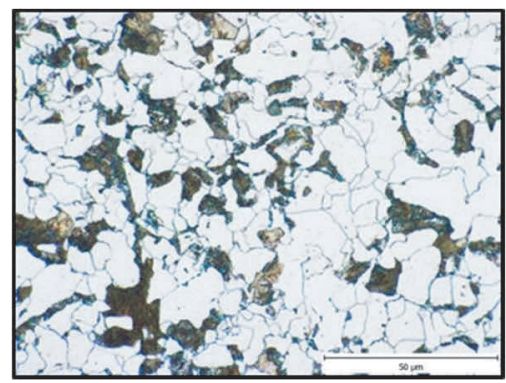

Deformation 0.7

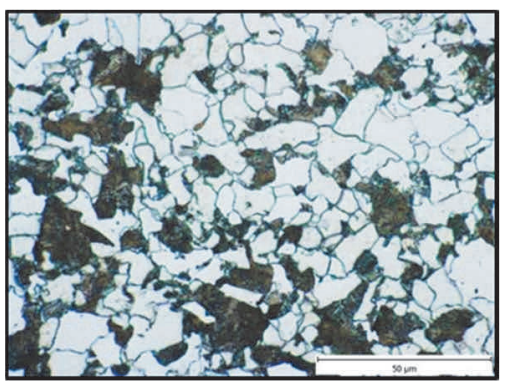

Deformation 2

Figure 8 Microstructure of selected, dilatometrically tested samples for a cooling rate of $0.2{ }^{\circ} \mathrm{C} / \mathrm{s}$

An increase in the cooling rate to $4{ }^{\circ} \mathrm{C} / \mathrm{s}$ and above led to the initiation of haze formation, as confirmed by metallographic analyzes in Figure 9 . The microstructure of samples cooled at $4{ }^{\circ} \mathrm{C} / \mathrm{s}$ was a mixture of polyhedral ferrite, pearlite and bainite over the entire range of deformations. Again, the different magnitude of the deformation resulted in different distribution of the represented structural components and possible ferrite refinement depending on the increasing deformation.

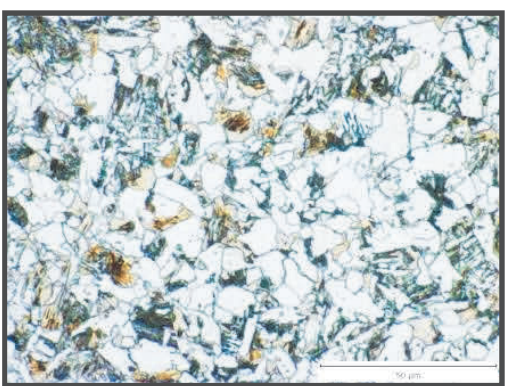

Deformation 0.15

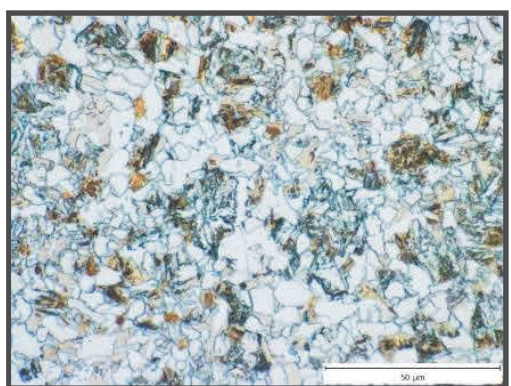

Deformation 1

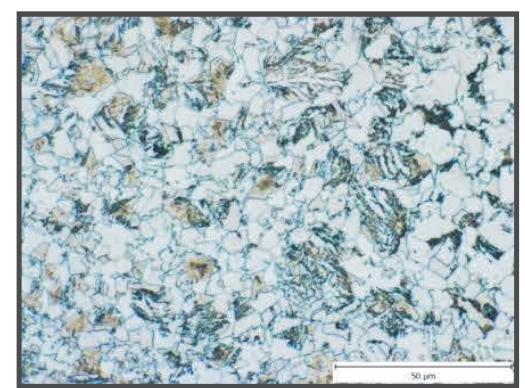

Deformation 2

Figure 9 Microstructure of selected, dilatometrically tested samples for a cooling rate of $4{ }^{\circ} \mathrm{C} / \mathrm{s}$

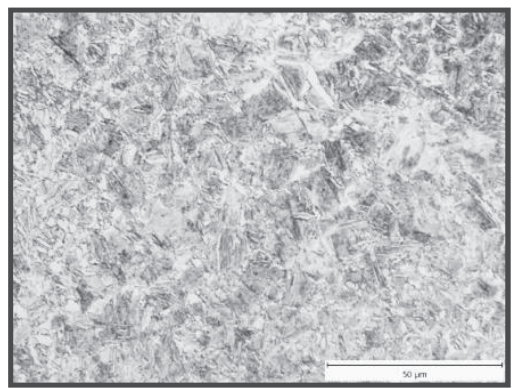

Without deformation

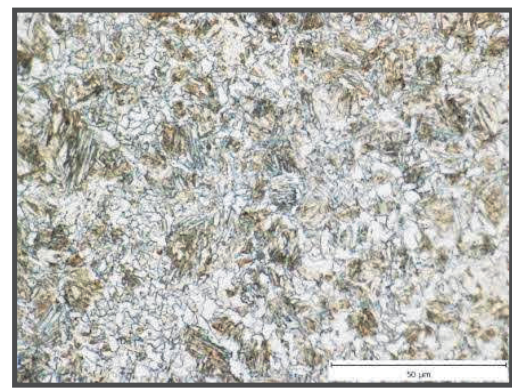

Deformation 0.35

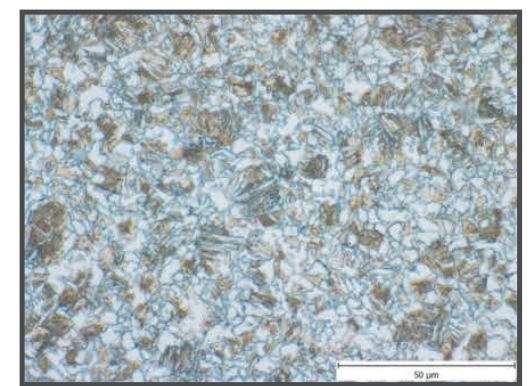

Deformation 2

Figure 10 Microstructure of selected, dilatometrically tested samples for a cooling rate of $35^{\circ} \mathrm{C} / \mathrm{s}$

In the studied steel, the highest chosen cooling rate led mainly to the formation of turbid components (bainite and martensite) and ferrite. Pearlite was no longer recorded in these structures. However, there was a fundamental influence of deformation, where the undeformed structure of the sample after cooling at $35{ }^{\circ} \mathrm{C} / \mathrm{s}$ contains only a minimal amount of ferrite and martensite predominates in the structure, otherwise 
the sample structure after deformation 2 is relatively evenly distributed between ferrite, bainite and martensite. This fact, coupled with a slightly increasing ferritic grain size, as a function of increasing deformation, confirms the acceleration of the ferritic transformation in the (D)CCT diagrams. Examples of microstructures after cooling at $35^{\circ} \mathrm{C} / \mathrm{s}$ and various deformation variants are shown in Figure 10.

Furthermore, the hardness of samples after selected temperature-deformation modes was analyzed. The course of the measured hardness in relation to the cooling rate and the magnitude of the deformation is given in Figure 11. It has been confirmed that hardness increases with increasing cooling rate. From the point of view of the influence of the deformation on the measured hardness, no significant differences were found. However, according to the assumptions of the highest cooling rate, the accelerating effect of the deformation on the ferritic transformation was manifested, which caused a decrease in hardness compared to the undeformed samples, which is also consistent with metallographic analyses. All these partial conclusions are summarized in a 3D graph in Figure 12.

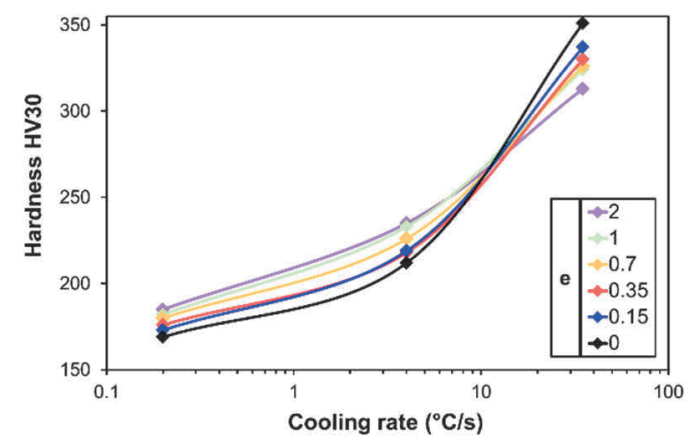

Figure 11 Influence of the cooling rate and deformation on hardness HV30

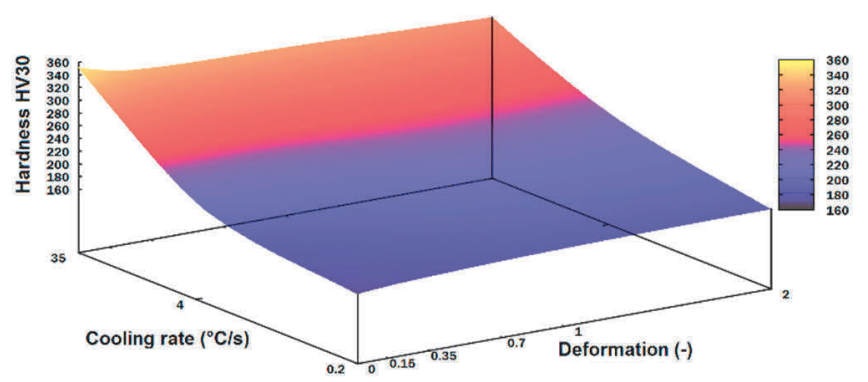

Figure 12 Influence of the cooling rate and deformation on hardness HV30

The development of hardness and proportions of structural components in combination with the average size of ferritic grains, depending on the size of the previous deformation and the cooling rate, is graphically demonstrated in Figure 13. These graphs clearly illustrate which transformations have had a major impact on the measured hardness. Furthermore, it can be seen that the size of the ferritic grains was not significantly affected by the previous deformation.

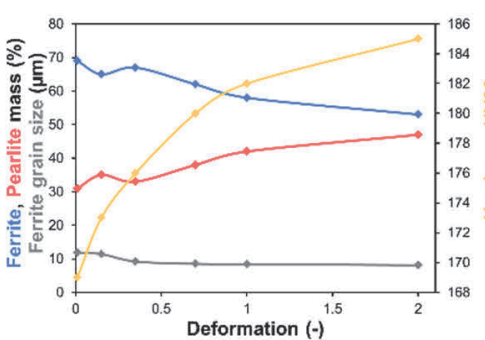

Cooling rate $0.2^{\circ} \mathrm{C} / \mathrm{s}$

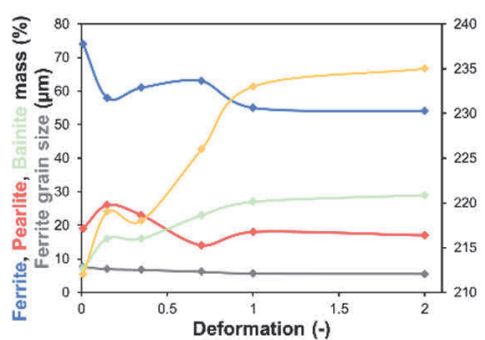

Cooling rate $4{ }^{\circ} \mathrm{C} / \mathrm{s}$

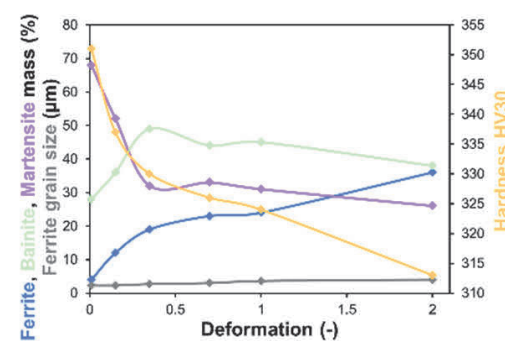

Cooling rate $35^{\circ} \mathrm{C} / \mathrm{s}$

Figure 13 Evolution of shares of structural components, hardness and size of ferritic grains depending on the deformation size and cooling rates

As a supplement to the works performed and knowledge acquired, unique 3D graphs were created (Figure 14), which describe the influence of the cooling rate and deformation size on individual transformation temperatures. 


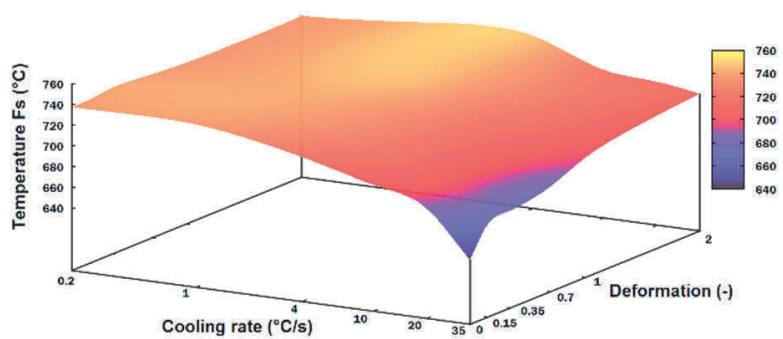

Ferrite start

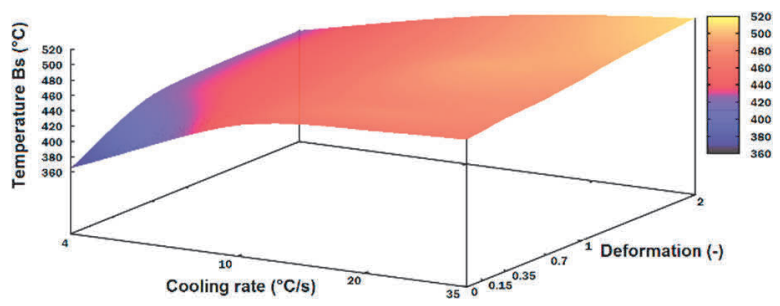

Bainite start

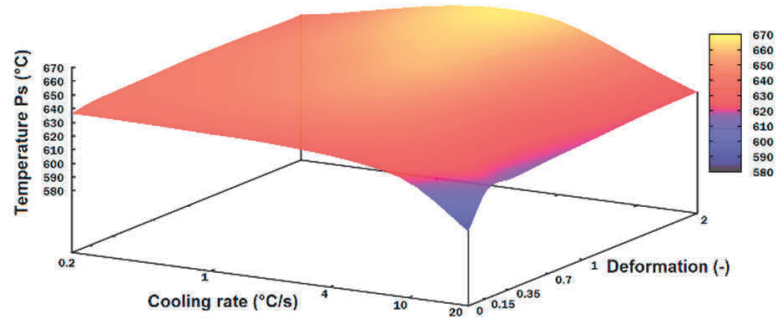

Pearlite start

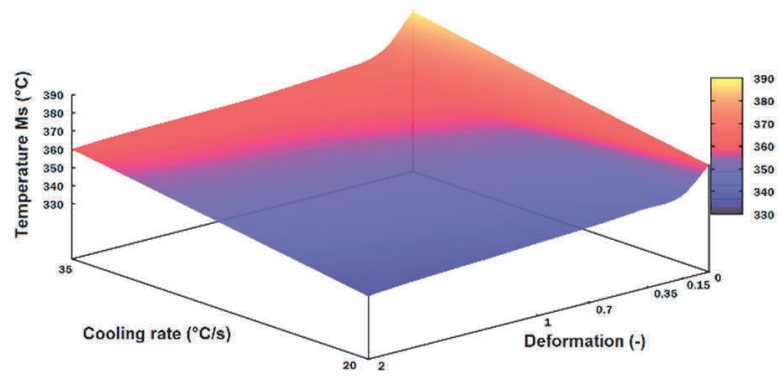

Martensite start

Figure 14 3D graphic dependencies of the commencements of selected transformation temperatures on the size of the deformation and cooling rate

\section{CONCLUSION}

The experiments performed proved that due to the increasing deformation, the temperature of the origin of ferrite and pearlite formation increases and thereby leads to the acceleration of both transformations controlled by the diffusion mechanism. This phenomenon manifested itself in both cases at higher cooling rates, with the maximum temperature difference between the undeformed state and deformation 2 at the highest cooling rate $\left(35^{\circ} \mathrm{C} / \mathrm{s}\right)$ reaching $70^{\circ} \mathrm{C}$.

The onset of bainitic conversion also increased with increasing deformation value, without a clear trend of cooling rate dependence. Conversely, the martensitic conversion, or the temperature of the beginning of martensite formation, respectively, decreased both with decreasing cooling rate and also with the magnitude of deformation, which may be associated with local depletion of carbon structures due to acceleration of the remaining transformations, thereby decreasing as the temperature of Ms decreases with increasing carbon content.

\section{ACKNOWLEDGEMENTS}

This paper was created at the Faculty of Materials Science and Technology within the Project No. CZ.02.1.01/0.0/0.0/17_049/0008399 funded by the Ministry of Education, Youth and Sports of the Czech Republic; and within the students' grant project SP2019/86 supported at the VŠB - TU Ostrava by the Ministry of Education of the Czech Republic.

\section{REFERENCES}

[1] GRAJCAR, A., KUZIAK, R., ZALECKI, W. Designing of cooling conditions for Si-Al microalloyed TRIP steel on the basis of DCCT diagrams. Journal of Achievements in Materials and Manufacturing Engineering. 2011. vol. 45, no. 2, pp. 115-124. 
[2] OPĚLA, P., SCHINDLER, I., KAWULOK, P., VANČURA, F., KAWULOK, R., RUSZ, S., PETREK, T. Hot flow stress models of the steel C45. Metalurgija. 2015. vol. 54, no. 3, pp. 469-472.

[3] JANDOVÁ, D., VADOVICOVÁ, L. Influence of deformation on austenite decomposition of steel 0.5C-1Cr-0.8Mn0.3Si, In: Metal 2004. Ostrava: TANGER, 2004, paper no. 223.

[4] KAWULOK, R., KAWULOK, P., SCHINDLER, I., OPĚLA, P., RUSZ, S., ŠEVČÁK, V., SOLOWSKI, Z. Study of the effect of deformation on transformation diagrams of two low-alloy manganese-chromium steels. Archives of Metallurgy and Materials. 2018. vol. 63, no. 4, pp. 1735-1741.

[5] TRZASKA, J., DOBRZAÑSKI, L.A. Modelling of CCT diagrams for engineering and constructional steels. Journal of Materials Processing Technology. 2007. vol. 192-193, pp. 504-510.

[6] KRUGLOVA, A.A., ORLOV, V.V. Effect of hot plastic deformation in the austenite interval on structure formation in low- alloyed - carbon steels. Metal Science and Heat Treatment. 2007. vol. 12, no. 11-12, pp. 556-560.

[7] TIMOSHENKOV, A., et al. Influence of Deformation on Phase Transformation and Precipitation of Steels for Oil Country Tubular Goods. Steel Research International. 2014. vol. 85, no. 6, pp. 954-967.

[8] NIKRAVESH, M., NADEIRI, M., AKBARI, G.H. Influence of Hot Plastic Deformation and Cooling Rate on Martensite and Bainite Start Temperatures in 22MnB5 steel. Materials Science and Engineering A. 2012. vol. 540, no. 1, pp. 24-29.

[9] YAMAMOTO, S., YOKOYAMA, H., YAMADA, K., NIIKURA, M. Effects of austenite Grain Size and Deformation in the Unrecrystallized Austenite Region on Bainite Transformation Behavior and Microstructure. ISIJ International. 1995. vol. 35, no. 8, pp. 1020-1026.

[10] KAWULOK, R., SCHINDLER, I., MIZERA, J., KAWULOK, P., RUSZ, S., OPĚLA, P., PODOLINSKY, P., ČMIEL, K.M. Transformation diagrams of selected steel grades with consideration of deformation effect. Archives of Metallurgy and Materials. 2018. vol. 63, no. 1, pp. 55-60.

[11] NÜRNBERGER, F., GRYDIN, O., SCHAPER, M., BACH, F.W., KOCZURKIEWICZ, B., MILENIN, A. Microstructure transformations in tempering steels during continuous cooling from hot forging temperatures. Steel Research International. 2010. vol. 81, no. 3, pp. 224-233.

[12] YIN, S.B., SUN, X.J., LIU, Q.Y., ZHANG, Z.B. Influence of Deformation on Transformation of Low-Carbon and High Nb-Containing Steel During Continuous Cooling. Journal of Iron and Steel Research, International. 2010. vol. 17 , no. 2 , pp. 43-47.

[13] https://www.bolzano.cz/assets/files/TP/Trubky/bezesve/MOP EN10216-3 2.pdf

[14] MOTYČKA, P., KÖVÉR, M. Evaluation methods of dilatometer curves of phase transformations. in: Comat 2012, Pilsen: Tanger Ltd, paper no. 1237.

[15] GRAJCAR, A., ZALECKI, W., SKRZYPCZYK, P., KILARSKI, A., KOWALSKI, A., KOŁODZIEJ, S. Dilatometric study of phase transformations in advanced high-strength bainitic steel. Journal of Thermal Analysis and Calorimetry. 2014. vol. 118, no. 2, pp. 739-748. 